\title{
Comparative Analysis of Three Prospective Trials of Multifocal Implants
}

\author{
S. P. B. PERCIVAL and S. S. SETTY \\ Scarborough
}

\begin{abstract}
Summary
A clinical analysis of best cases four to 12 months postoperatively was made to assess the function of $473 \mathrm{M}$ multifocal implants, 40 Iolab multifocal implants and 24 AMO multifocal implants. Overall $86(79 \%)$ eyes could see $6 / 12$ and N6 unaided. The multifocal function for each lens worked well for distance, intermediate and near in the majority but an increase in depth of field was at a cost of reduced resolution efficiency. The $3 \mathrm{M}$ lens was associated with symptoms of poor optical quality in $\mathbf{2 9 . 8 \%}$ and with an inability to read $\mathrm{N} 5$ with correction in $17 \%$. The Iolab lens provided better reading vision but less good distant vision than the other types and was associated with symptoms of poor optical quality in $15 \%$. Many of these had a pupil diameter greater than $3.5 \mathrm{~mm}$. The AMO lens gave a poorer unaided reading vision than the other lens types but had the lowest incidence of optical symptoms.
\end{abstract}

The first report concerning the validity of a bifocal implant occurred in $1987 .{ }^{1}$ Since then, many manufacturers have brought new designs onto the market but broadly, of four different types: (a) the two or three zone refraction type wherein a central disc of the lens has one focus and a surrounding annulus with a refracting surface of a different radius of curvature has another; (b) the diffraction type wherein some thirty annular zones are separated by stepped discontinuities which result in diffraction of light and destructive/ constructive interference, such that the light from every zone is brought predominantly towards two focal points; (c) multizone refraction type wherein there are five zones each with a progressive focus due to a (proprietary) undulating refractive surface; (d) the aspheric type wherein one part of the lens has a continuously changing radius of curvature and therefore a graduated alteration in focus. $^{2}$
This paper attempts to analyse the clinical effects from the first three above mentioned designs.

\section{Material and Methods}

One hundred and eleven patients without other ocular pathology such as macular degeneration and who had survived at least four months following their lens implantation, were entered into the study. They were taken from three different sources: (a) forty: seven consecutive patients implanted with a $3 \mathrm{M}$ diffractive bifocal lens, 8 Style 834LE, 39 Style 815LE, between March 1988 and February 1989; (b) forty consecutive patients implanted with an Iolab two zone refractive bifocal lens, Style 6840M, between June 1989 and April 1990; (c) twenty-four consecutive patients implanted with an Allergan Medical Optics (AMO) Array design (multizone refraction) Style MPC25, between June 1990 and February 1991. 
Table I Manufacturer's theoretical guide to proportionate distribution of light (\%) according to pupil size

\begin{tabular}{lcccccc}
\hline & \multicolumn{2}{c}{$3 M$} & \multicolumn{2}{c}{ Iolab } & \multicolumn{2}{c}{ AMO } \\
Pupil size & Distance & Near & Distance & Near & Distance & Near \\
\hline $2.4 \mathrm{~mm}$ & 41 & 41 & 30 & 70 & 60 & 22 \\
$2.8 \mathrm{~mm}$ & 41 & 41 & 50 & 50 & 50 & 38 \\
$4.0 \mathrm{~mm}$ & 41 & 41 & 75 & 25 & 50 & 35 \\
\hline
\end{tabular}

Thirty-nine patients were male and 72 were female. The mean age at surgery was 74.6 years (range 44-95). There was no significant difference in age or sex between the three groups.

The $3 \mathrm{M}$ lens comprised a clear $0.6 \mathrm{~mm}$ central zone for distant vision, and multiple annular diffracting zones each of which theoretically focused a maximum of $41 \%$ of light for distance and $41 \%$ for near ${ }^{2}$ differing by a power of $3.5 \mathrm{D}$ equivalent to $2.3 \mathrm{D}$ spectacle correction. The light distribution was theoretically independent of pupil size and centration.

The Iolab lens comprised a central $2 \mathrm{~mm}$ zone of power 4.0D greater than the peripheral zone, equivalent to $2.5 \mathrm{D}$ difference in spectacle correction, the central zone being for near vision and the peripheral zone for distant vision. The ratio of light distribution would vary between the zones according to pupil size and lens centration but theoretically for normal centration would be $50: 50$ with a pupil diameter of $2.8 \mathrm{~mm}$ changing to $75 \%$ for distance and $25 \%$ for near with a pupil diameter of $4.0 \mathrm{~mm}$ (Table I).

The AMO lens comprised a $2.1 \mathrm{~mm}$ central zone for distant vision (but incorporating some intermediate focus outside the central $1.0 \mathrm{~mm} \mathrm{disc}$ ), outside of which there were four annular zones each refracting light progressively through a focus varying between 0 and $3.5 \mathrm{D}$ greater than the central zone. The theoretical proportionate light distribution for a pupil size of $2.8 \mathrm{~mm}$ was $50 \%$ for dis- tance, $38 \%$ for near and $12 \%$ for intermediate foci, and for a pupil size of $4.0 \mathrm{~mm}$ was $50 \%$ for distance, $35 \%$ for near and $15 \%$ for intermediate foci (Table I). The light distribution of this truly multifocal lens was therefore theoretically independent of lens centration and of pupil sizes greater than $2.1 \mathrm{~mm}$.

Comparison of the function of these lens types in clinical practice was made four to 12 months after surgery by:

1. Assessment of the ability to see $6 / 12$ and N6 (which are equivalent acuities) without correction.

2. Patients were asked to read in a good light with the operated eye $\mathrm{N} 5$ at any distance between 25 and $35 \mathrm{~cm}$, with the distant correction.

3. Assessment of visual acuity using a Snellen chart at $6 \mathrm{~m}$ (a) with the distant spectacle correction, (b) with a $-1.25 \mathrm{D}$ lens added (for intermediate vision), (c) with a $-2.5 \mathrm{D}$ lens added (for near vision). In this way, near, distance and intermediate could be compared using the same testing conditions.

4. Subjective assessment of the optical quality (a) by assessing whether the optical quality for near could be improved when the distance focus of the implant was used with a reading addition (only those preferring a reading addition in excess of $1.5 \mathrm{D}$ were included in this group), and (b) by asking whether the patient when fully corrected, complained of blurred vision or ghosting or haloes from a second image. Asympto-

Table II Snellen visual acuities for 47 eyes with 3 M implants (\%)

\begin{tabular}{lccc}
\hline Visual acuity & $\begin{array}{c}\text { Distance } \\
\text { correction }\end{array}$ & $\begin{array}{c}\text { Intermediate } \\
-1.25 D \text { added }\end{array}$ & $\begin{array}{c}\text { Near } \\
-2.5 D \text { added }\end{array}$ \\
\hline $6 / 6$ or $6 / 5$ & $28(59.6)$ & 0 & $14(29.8)$ \\
$6 / 9$ & $18(38.3)$ & $15(31.9)$ & $19(40.4)$ \\
$6 / 12$ or $6 / 18$ & $1(2.1)$ & $30(63.8)$ & $14(29.8)$ \\
$6 / 24$ or $6 / 36$ & 0 & $2(4.3)$ & 0 \\
\hline
\end{tabular}


Table III Snellen visual acuities for 40 eyes with Iolab implants (\%)

\begin{tabular}{lccc}
\hline Visual acuity & $\begin{array}{c}\text { Distance } \\
\text { correction }\end{array}$ & $\begin{array}{c}\text { Intermediate } \\
-1.25 D \text { added }\end{array}$ & $\begin{array}{c}\text { Near } \\
-2.5 D \text { added }\end{array}$ \\
\hline $6 / 6$ or $6 / 5$ & $12(30.0)$ & $1(2.5)$ & $16(40.0)$ \\
$6 / 9$ & $25(62.5)$ & $13(32.5)$ & $20(50.0)$ \\
$6 / 12$ or $6 / 18$ & $3(7.5)$ & $21(52.5)$ & $3(7.5)$ \\
$6 / 24$ or $6 / 36$ & 0 & $5(12.5)$ & $1(2.5)$ \\
\hline
\end{tabular}

matic patients entirely satisfied, who admitted to occasional blurring or doubling under certain lighting when prompted with leading questions, were not included.

Statistical analysis was by Armitage's standardised normal deviate and where appropriate by Fisher's two tailed exact test.

\section{Results}

The percentage of patients able to see both $6 / 12$ and N6 unaided was $76.5 \%$ in the $3 \mathrm{M}$ group (36/47), $80.0 \%$ in the Iolab group (32/ $40)$ and $75.0 \%$ in the AMO group (18/24).

The proportion of eyes able to read N5 in a good light between 25 and $35 \mathrm{~cm}$ with the distance correction was $27 / 473 \mathrm{M}$ cases $(57.4 \%)$, $36 / 40$ Iolab cases $(90 \%)$ and 19/24 AMO cases (79.2\%).

Tables II to IV show that a significantly higher proportion of patients with the AMO or $3 \mathrm{M}$ implants were able to see $6 / 6$ or $6 / 5$ when corrected for distance, than with the Iolab implant $(\mathrm{p}=0.003)$. The intermediate vision (Snellen with $-1.25 \mathrm{D}$ added to the distance correction) showed a range from $6 / 6$ to $6 / 24$ in each group with no significant difference between the groups. Near vision (Snellen with $-2.5 \mathrm{D}$ added) was significantly better for Iolab lenses ( $p=0.0002$ when compared with AMO lenses and $\mathrm{p}=0.03$ when compared with $3 \mathrm{M}$ lenses) with $90 \%$ seeing $6 / 9$ or better.

Deficiencies in the multifocal function are evident from some poor achievements in the near vision columns of Tables II-IV and are highlighted by Table V. Eight $(17.0 \%)$ of the $3 \mathrm{M}$ eyes could not read N5 even with a reading addition and $14(29.8 \%)$ complained of a blur, shadow or ghosting, when reading small print. The lens giving rise to the fewest symptoms appeared to be the AMO lens with only one patient complaining of a blur $(4.2 \%)$. The Iolab eyes achieved good reading with the distance correction provided there was no abnormality of the pupil. Four $(10.0 \%)$ could not read N5 with the distance correction. The reason was a 3.5 to $4.5 \mathrm{~mm}$ pupil in three and decentration in one, when altered light distribution reduced the percentage of light to be focussed through the reading zone. All these complained of a blur or shadow when reading and one could not read $\mathrm{N} 5$ even with a reading addition. Two other patients complained of ghosting or shadowy vision (one for distance as well as near) making a total of six $(15.0 \%)$ who were aware of an optical deficit.

Table VI indicates the incidence of decentration greater than $0.5 \mathrm{~mm}$ with reference to the centre of the pupil as seen on the slit lamp, and the incidence of pupillary abnormality. Six of the $143 \mathrm{M}$ patients who were aware of an optical deficit, had a decentered lens with or without a pupillary abnormality. This was not of statistical significance. All except one of the six Iolab patients who were aware of a deficit had either an atonic pupil (three) or mild decentration (two). However there were six other patients with an Iolab lens and an abnormal pupil who had no symptoms. The high incidence of decentration among the $3 \mathrm{M}$

Table IV Snellen visual acuities for eyes with AMO implants (\%)

\begin{tabular}{lccc}
\hline Visual acuity & $\begin{array}{c}\text { Distance } \\
\text { correction }\end{array}$ & $\begin{array}{c}\text { Intermediate } \\
-1.25 D \text { added }\end{array}$ & $\begin{array}{c}\text { Near } \\
-2.5 D \text { added }\end{array}$ \\
\hline $6 / 6$ or $6 / 5$ & $15(62.5)$ & $1(4.2)$ & 1 \\
$6 / 9$ & $8(33.3)$ & $8(33.3)$ & $10(41.7)$ \\
$6 / 12$ or $6 / 18$ & $1(4.2)$ & $14(58.3)$ & $13(54.1)$ \\
$6 / 24$ or $6 / 36$ & 0 & $1(4.2)$ & 0 \\
\hline
\end{tabular}


Table $\mathbf{V}$ Number (\%) with visual deficits from the multifocal implants

\begin{tabular}{lccc}
\hline & $3 M$ & Iolab & AMO \\
\hline $\begin{array}{l}\text { Unable to read N5 with any correction } \\
\text { (between } 25 \text { and } 35 \mathrm{~cm} \text { ) }\end{array}$ & $8(17.0)$ & $1(2.5)$ & 0 \\
$\begin{array}{l}\text { Complaint of blur or ghosting from } \\
\text { second image }\end{array}$ & $14(29.8)$ & $6(15.0)$ & $1(4.2)$ \\
$\begin{array}{l}\text { Preference for distance focus for } \\
\text { reading (additional 1.5D or more }\end{array}$ & $6(12.8)$ & $3(7.5)$ & $9(37.5)$ \\
required for reading glasses)
\end{tabular}

lenses may reflect the fact that these were not of a single piece design.

\section{Discussion}

Holladay and others have evaluated the optical performances of several multifocal lenses including the three evaluated clinically in this paper. They showed using laboratory and photographic studies, and a simulated $3.0 \mathrm{~mm}$ pupillary aperture, a $50 \%$ reduction in contrast in the retinal image, a one line drop in best corrected acuity, but a two to threefold increase of depth of field for all multifocal lenses when compared to a monofocal lens. The resolution efficiency was similar for each of the multifocal lenses tested. ${ }^{3}$ Loss of image quality has also been demonstrated photographically by Zisser and Guyton. ${ }^{4}$

The results of our objective testing clinically support these studies although the AMO multifocal did not appear to be associated with any significant drop in best corrected acuity. This may have been due to the small number sampled or the fact that the postoperative size of normal pupils, that is of eyes excluding the three listed in Table VI, was found to average at $2.6 \mathrm{~mm}$ rather than $3.0 \mathrm{~mm}$ so reducing capacity of the near focus zones. The increase in depth of field was best exemplified by the Iolab lens with $90 \%$ reading N5 with the distant correction.

Subjective assessment of patient satisfaction may be coloured by expectation, accuracy of the implant power calculation, past experience, motivation to be without glasses and need for optimum correction for the fellow eye. For this reason we have not reported on the ability to manage without glasses. One person may be content with unaided vision of $6 / 6$ and $\mathrm{N} 6$ at $35 \mathrm{~cm}$ : another with $\mathrm{N} 5$ at $35 \mathrm{~cm}$ will not be content unless glasses are provided to give an accommodative reserve with $\mathrm{N} 5$ at $25 \mathrm{~cm}$.

In practice we found the AMO lenses to be the least likely to give rise to symptoms. The multifocal function was not as good as that of the Iolab lenses but with $75 \%$ seeing $6 / 12$ and N6 unaided, and 79\% seeing N5 with the distance correction, was considerably better than might be expected from a monofocal implant. A previous analysis of 55 best case monofocal implants showed an incidence of $31 \%$ seeing $6 / 12$ and $\mathrm{N} 6$ unaided and $2 \%$ seeing $\mathrm{N} 5$ with the distance correction. ${ }^{5}$ We considered this to be the safest of the three lens types, being distance dominant (Table I) and because reading acuity could always be improved by the addition of reading spectacles. This in fact was the preferred option for $9 / 24(37.5 \%)$ patients (Table V).

The 3M lens gave excellent results in the majority but presented a deficit in optical quality for $29.8 \%$ of patients, who noted some shadow for small print and included $17 \%$ who were unable to read N5. Others also have noted a defect with these lenses: the $3 \mathrm{M}$ European multicentre trial found $14 \%$ of 280 best case' eyes unable to read N5 with best correc-

Table VI Incidence of decentration and pupillary abnormality (\%)

\begin{tabular}{lrrr}
\hline & $3 M$ & Iolab & AMO \\
\hline Decentration more than 0.5 mm & $14(29.8)$ & $2(5.0)$ & $2(8.3)$ \\
$\begin{array}{l}\text { Pupil eccentricity, segmental atony, or } \\
\text { diameter in moderate illumination }\end{array}$ & $6(12.8)$ & $9(22.5)$ & $3(12.5)$ \\
greater than 3.4 mm & & & \\
\hline
\end{tabular}


tion $^{6}$ and Deutman noted an incidence of $25 \%$ being unable to read N5 with best correction. ${ }^{7}$ Haigis and others also noted deficiencies in the image quality ${ }^{8}$ and Ellingson commented on the high incidence of explantation because of poor optical quality. ${ }^{9}$ Our incidence of explantation is three out of $563 \mathrm{M}$ multifocals implanted $(5.4 \%)$, all for reasons of unacceptable optical quality.

The Iolab lens gave the best multifocal result with $80 \%$ seeing $6 / 12$ and $\mathrm{N} 6$ unaided and $90 \%$ reading $\mathrm{N} 5$ with the distance correction, but possibly at the expense of a slight reduction in distance acuity (Table III). Only $30 \%$ could see $6 / 6$ or better with the distance correction whereas analysis of best cases six months after surgery should reveal at least $70 \%$ seeing $6 / 6$ or better. ${ }^{10,11}$ However, the main problem with this lens was that decentration or a pupillary abnormality could lead to an altered light distribution between the two foci with the result that occasionally, neither the reading focus, nor the distance focus with a reading addition, gave an acceptable quality.

In conclusion, it is felt that surgeons should be made aware that no multifocal can give a perfect result in all cases and that although the human brain can adapt to the process of simultaneous imaging, whereby images from out of focus light are ignored, they may not be ignored completely. Resolution may be compromised because the performance of each lens is partly determined by the degree to which contrast at the focussed image is reduced by out of focus images.

It is incumbent on all surgeons who wish to advise a multifocal lens to assess thoroughly the patient's tolerance to slightly indistinct vision. Multifocals should not be advised for professionals who may wish to read quickly, nor in the presence of any sight threatening defect such as macular degeneration. Care should be taken to ensure compatibility with the refraction of the fellow eye and finally, with the surgeon's own ability to achieve a result near to emmetropia.

KEY wORDS: Comparative analysis, Multifocal implants, Optical deficit, Visual acuities.

\section{References}

1 Keates RH, Pearce JL, Schneider RT: Clinical results of the multifocal lens. J Cataract Refractive Surg 1987, 13: 557-60.

${ }^{2}$ Duffey RJ, Zabel RW, Lindstrom RL: Multifocal intraocular lenses. In Percival SPB, ed. A Colour Atlas of Lens Implantation, London: Wolfe Publishing Ltd., 1991, 133-136.

${ }^{3}$ Holladay JT, van Dijk H, Lang A, Portney V, Willis TR, Sun R, Oksman HC: Optical performance of multifocal intraocular lenses. J Cataract Refractive Surg 1990, 16: 413-22.

${ }^{4}$ Zisser HC and Guyton DL: Photographic simulation of image quality through bifocal intraocular lenses. Am J Ophthalmol 1989, 108: 324-6.

${ }^{5}$ Percival SPB: Prospective study of new diffractive bifocal intraocular lens. Eye 1989, 3: 571-5.

${ }^{6}$ European multicentre study clinical data summary: 3M Vision Care Technical Bulletin: February 1990.

${ }^{7}$ Deutman A: Communication to the Netherlands Intraocular Implant Club, Gronigen, November 1990.

${ }^{8}$ Haigis W, Klatt B, Reiner J, Guthoff R: Vergleichende Messungen zur Abbildungsqualitat von mono-und multifokalen intrakularlinsen. Communication to the German Society for Intraocular lens Implantation. Essen March 1990.

${ }^{9}$ Ellingson FT: Explantation of $3 \mathrm{M}$ diffractive intraocular lenses. J Cataract Refractive Surg 1990, 16: 697-702.

${ }^{10}$ Oxford Cataract Treatment and Evaluation Team: Subjective assessment of the effect of cataract surgery and a review of long-term aims. Eye 1987, 1: 247-53.

${ }^{11}$ Percival SPB: Prospective study comparing Hydrogel with PMMA lens implants. Ophthalmic Surg 1989, 20: 255-61. 